\title{
The Effect of Gamma Wave Optimization and Attention on Hitting Skills in Softball
}

\author{
Jajat Darajat Kusumah Negara ${ }^{1, *}$, Sufyar Mudjianto ${ }^{1}$, Astri Budikayanti ${ }^{2}$, Adhitya Nugraha PP $^{1}$ \\ ${ }^{1}$ Department of Sport Education, Faculty of Sport Education and Health, Universitas Pendidikan Indonesia, Bandung, 40154, West \\ Java, Indonesia \\ ${ }^{2}$ Department of Neurology, Faculty of Medicine, Universitas Indonesia, Jakarta, 10440, DKI Jakarta, Indonesia
}

Received September 22, 2020; Revised December 2, 2020; Accepted December 15, 2020

\section{Cite This Paper in the following Citation Styles}

(a): [1] Jajat Darajat Kusumah Negara, Sufyar Mudjianto, Astri Budikayanti, Adhitya Nugraha PP , "The Effect of Gamma Wave Optimization and Attention on Hitting Skills in Softball," International Journal of Human Movement and Sports Sciences, Vol. 9, No. 1, pp. 103-109, 2021. DOI: 10.13189/saj.2021.090114.

(b): Jajat Darajat Kusumah Negara, Sufyar Mudjianto, Astri Budikayanti, Adhitya Nugraha PP (2021). The Effect of Gamma Wave Optimization and Attention on Hitting Skills in Softball. International Journal of Human Movement and Sports Sciences, 9(1), 103-109. DOI: 10.13189/saj.2021.090114.

Copyright $(2021$ by authors, all rights reserved. Authors agree that this article remains permanently open access under the terms of the Creative Commons Attribution License 4.0 International License

\begin{abstract}
Hitting the ball is a complicated ability in softball academicie, because in appreciation to prioritizing movement skills, cognitive appearances additionally need to be investigated, one of which is attention. Meanwhile, going to hit the ball requires excellent attention for an individual student. Exhibiting gamma waves further influence arrangements of hitting performance. The objectives of this study were first, to determine the negative functional correlation between gamma brain waves and hitting skills, then second to know the positive functional correlation between attention and hitting skills and third to determine the effect of attention on increasing hitting skills The method used in this research is an experimental method with a one-group pretest-posttest design research design. The sampling technique in this study was using a saturated sampling technique. This investigation amounted to 20 subjects, in the calculation of the Pearson product-moment correlation test using SPSS v.23. The first results collected were $p$-value 0.026 with an $r$ square value of 0.25 , so there is a significant negative functional correlation between gamma brain waves and hitting skills in softball learning of $25 \%$. The second issue obtained $\mathrm{p}$-value 0.017 with an $\mathrm{r}$ square value of 0.28 , so there is a significant positive functional correlation between attention and hitting skills in softball learning by $28 \%$. Furthermore, thirdly, the results obtained p-value 0.0001 between pre-test and post-test, with a significant increase in skills of $70.17 \%$, so there is a significant influence between attention and hitting skills.
\end{abstract}

Keywords Attention, Gamma Brain Waves, Hitting Skills, Softball Games

\section{Introduction}

The optimized state of performance reached by sport elites offers a privileged domain for studying the different neuronal oscillations linked to sensorimotor and cognitive control getting to final success or failure[1]. The human brain is the various vital glands for all life perspectives, including regulating all body functions, responding to all physical activities, and in the thought process in determining decisions. The human brain adapts to changing demands by altering its functional and structural properties neuroplasticity, which results in learning and acquiring skills[2]. Brain development, or learning, is the process of creating, strengthening, and discarding connections among the neurons; these connections are called synapses. Synapses organize the brain by forming pathways that connect the parts of the brain governing everything we do - from breathing and sleeping to thinking and feeling[3]. Brain is an organ that is easily affected by the physical changes, especially in modern times, when the increasing pollution quickly poisons people. When the poisonous substances enter the body, every organ, including the brain, will be endangered. Abnormalities will occur to the brain in terms of attention, 
memory, eyesight, intellect, and balance[3,4]. Attention is a complex cognitive process of selecting essential issues and ignoring those which are less critical. Attention and concentration both are equally important for physiological and behavioral responses.[5] When an individual is conscious, she/he possesses two types of attention, active and passive. Active attention is a voluntary process of increased alertness, concentration, interest, and needs. Curiosity and hunger are the stimulants for active attention. Passive attention can be an involuntary cognitive process that quickly gets distracted by any external stimuli[6].

The aim of study is how the brain oscillating attention and hitting performance. Learning to perform well in sports is difficult and time-consuming. Sports often involve physical tasks that require specific choreography in order to be most effective. For example, golf swings, tennis serves, basketball free throws, and martial arts kicks all involve a series of movements that must be appropriately timed and executed. Acquiring the physical skills necessary to perform such movements well requires three steps: (1) task definition, (2) practice, and (3) performance assessment. The process is iterative and continues indefinitely, with feedback from performance assessment at each step revising the task definition[7]. The brain's functional appearance is influenced by fluctuating brain waves, depending on a person's psychological state[8]. Brain waves are generated from activities between neurons in the brain that are interconnected with each other to deliver information which eventually causes vibrations and produces a type of wave that is divided into several types of brain waves based on their frequency, namely gamma, beta, alpha, theta, and delta[8]. As research found by Cheron et al., it is necessary to pay attention to achieving the brain's best performance because it determines motor and psychological controls such as motivation, attention, goal setting, memory, self-control, and decision making[1]. Another fact shows that gamma brain waves occur when a person is fully conscious or very alert. Gamma waves are useful in increasing attention, perception, and memory. Excessive stress or anxiety, such as public appearances, panic, and fear, will cause a relatively high increase in gamma waves[9].

Softball games can provide benefits and stimulator, both psychomotor, cognitive, and productive[10]. Many children or adolescents have difficulty playing softball because softball is relatively more difficult. After all, it is associated with a high degree of accuracy, so they experience stress or anxiety[10,11]. The key to successful batting is practice. Batting drills allow the batter to perform many swings quickly, which is essential because muscle memory depends on repetition, and each drill helps the batter focus on one particular aspect of the swing, accelerating the learning. Good practice will enhance performance, and each swing must be executed to perfection. Remember, only perfect practice makes perfect. The drills included in this section are some examples. Use imagination and compile others[12].

Sherwin's research has shown that many players experience difficulty in hitting movements because the hitter must predict and decide quickly and accurately in order to produce the right motor response[13].Other studies have shown that quick and precise decision making plays a vital role in hitting motion - the functional result of the brain in the form of gamma waves[14]. Other evidence by Castaneda found that a skilled hitter pays attention to external factors (pitcher and ball direction) while a less skilled hitter gives more attention to internal factors (hitting motion)[15].

\section{Materials and Methods}

Neurosky Mindwave Mobile's is an electroencephalograph (EEG) research instrument that detects gamma brain waves in the frequency range 32 $100 \mathrm{~Hz}$ range and WujiBrain software for mac v.127. Attention measurement using grid exercise concentration test and the O'Donnel fungo batting test to measure performance hitting skills.

The research subjects involved were Indonesia University of Education students with 20 male students applying simple random sampling and met the inclusion criteria. The subject's inclusion criteria were having exercised $>1$ year; male, and had no chronic disease background, had a BMI in the Normal category, agreed, and was willing to volunteer by filling in the consent information and ethical research. The duration of the study was three months, according to the research procedure. (See the figure 1). 


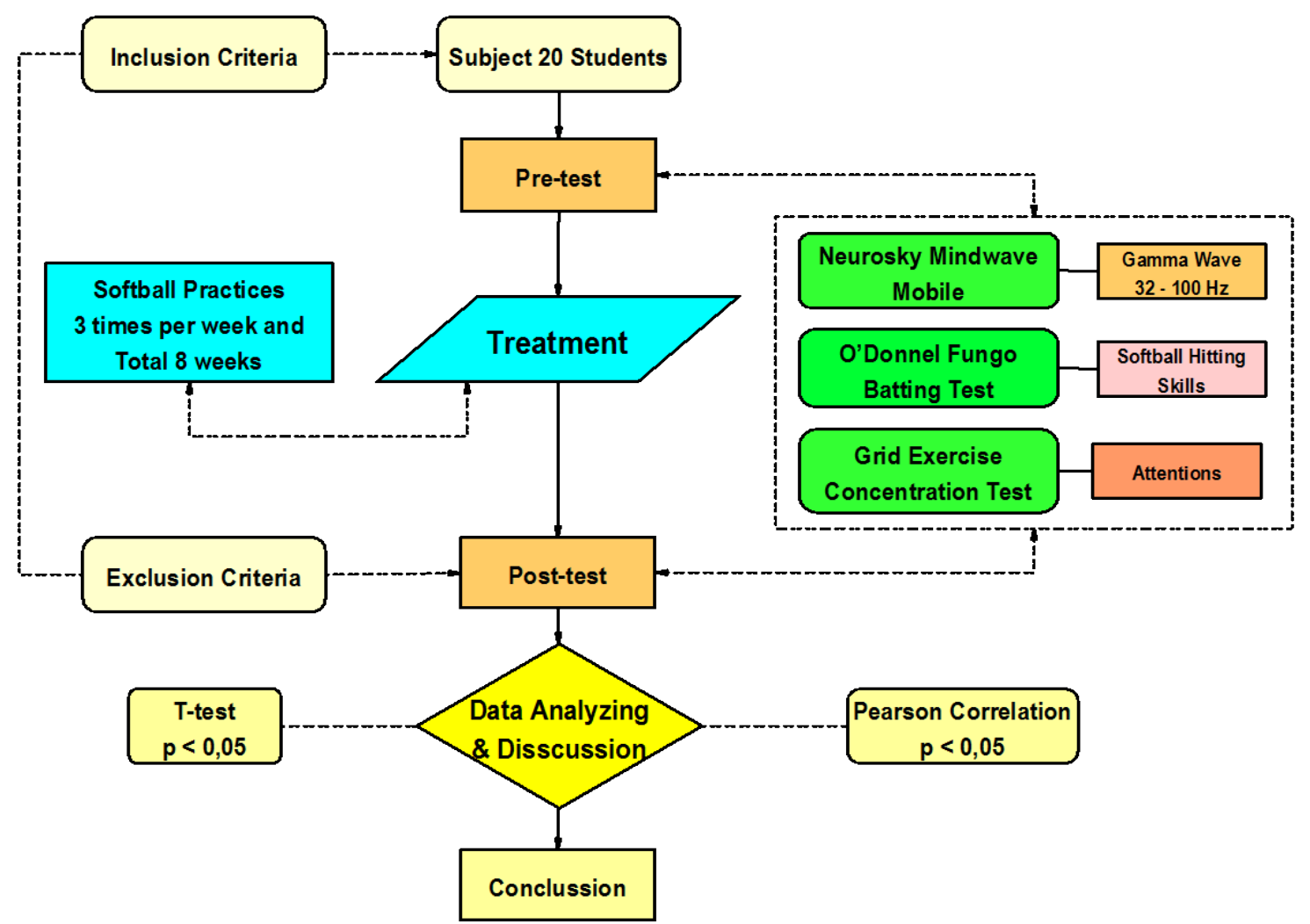

Figure 1. Research procedure. Research subjects must meet the inclusion criteria. In the first week, the initial measurements were carried out in gamma waves, softball hitting, and attention.

Test protocol: the subject's head is installed with Mindwave Mobile and ensured that it is safe and firmly attached to the head, then connect to a computer device and make sure that the device connected via Bluetooth with the Wujibrain v.127 software. The subject did a grid exercise test to measure attention for one minute, then immediately performed an O'Donnel test to measure 10x hitting skills. Treatment consists of regular softball training for beginners three times a week for eight weeks. The last week took the final measurement (same as the initial measurement). Data were collected and analyzed using XLSTAT v.2020.3.1 for mac software. To analyze the correlation between variables, the Pearson Correlation test was performed at $p<0.05$. Demography of subject consist of aged, height, weight and body mass index (see table 1). Percentage of mody mass index category (see fig 2). Gain-score of all variables with the parameters minimum value, maximum value, mean and standard deviation (see fig 3). Summary of gamma wave, attention, hitting performance (see table 2).

\section{Result}

Table 1. Demography of subjects

\begin{tabular}{ccccc}
\hline Variable & Mean \pm SD & Min & Max & N \\
\cline { 1 - 4 } Aged & $19,65 \pm 1,26$ & 17 & 22 & \\
\cline { 1 - 4 } Height $(\mathrm{m})$ & $1,70 \pm 0,05$ & 1,58 & 1,80 & \\
\cline { 1 - 4 } Weight $(\mathrm{Kg})$ & $63,40 \pm 10,05$ & 50 & 63 & \\
\cline { 1 - 4 } BMI & $21,98 \pm 3,68$ & 17,30 & 34,16 & \\
\hline
\end{tabular}

Table 2. Description of all variables data

\begin{tabular}{ccccc}
\hline \multicolumn{2}{c}{ Variables } & Min & Max & Mean \pm SD \\
\hline \multirow{2}{*}{$\begin{array}{c}\text { Gamma } \\
\text { waves }\end{array}$} & Pre & 86,64 & 95,83 & $90,96 \pm 2,26$ \\
\cline { 2 - 5 } & Post & 78,92 & 86,07 & $82,69 \pm 1,88$ \\
\hline \multirow{2}{*}{ Attentions } & Pre & 4,00 & 11,00 & $7,20 \pm 2,02$ \\
\cline { 2 - 5 } & Post & 9,00 & 18,00 & $12,65 \pm 2,79$ \\
\hline \multirow{2}{*}{ Hitting skills } & Pre & 23,67 & 32,67 & $27,45 \pm 2,03$ \\
\cline { 2 - 5 } & Post & 30,67 & 43,33 & $39,12 \pm 3,16$ \\
\hline
\end{tabular}




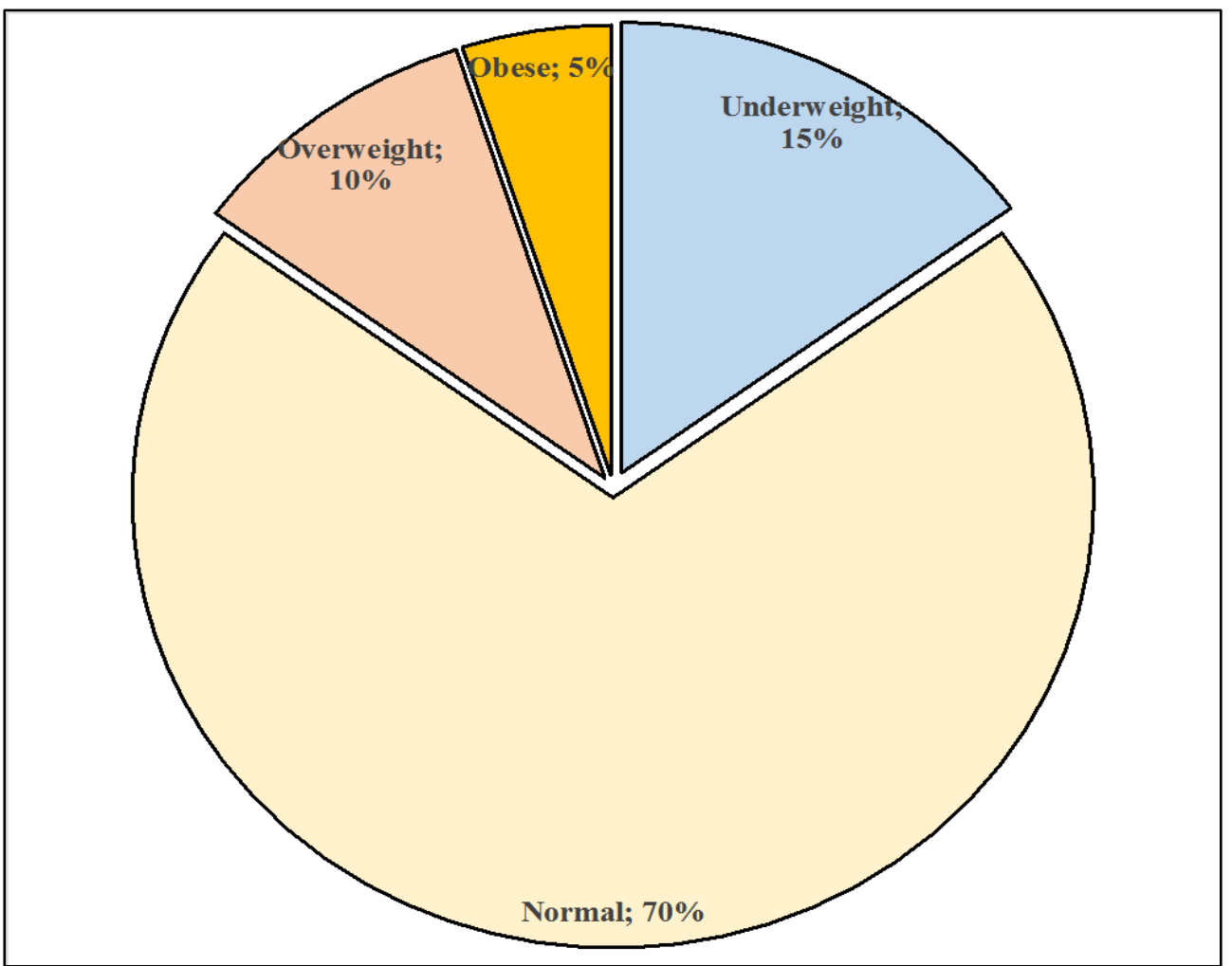

Figure 2. Percentage of body mass index category

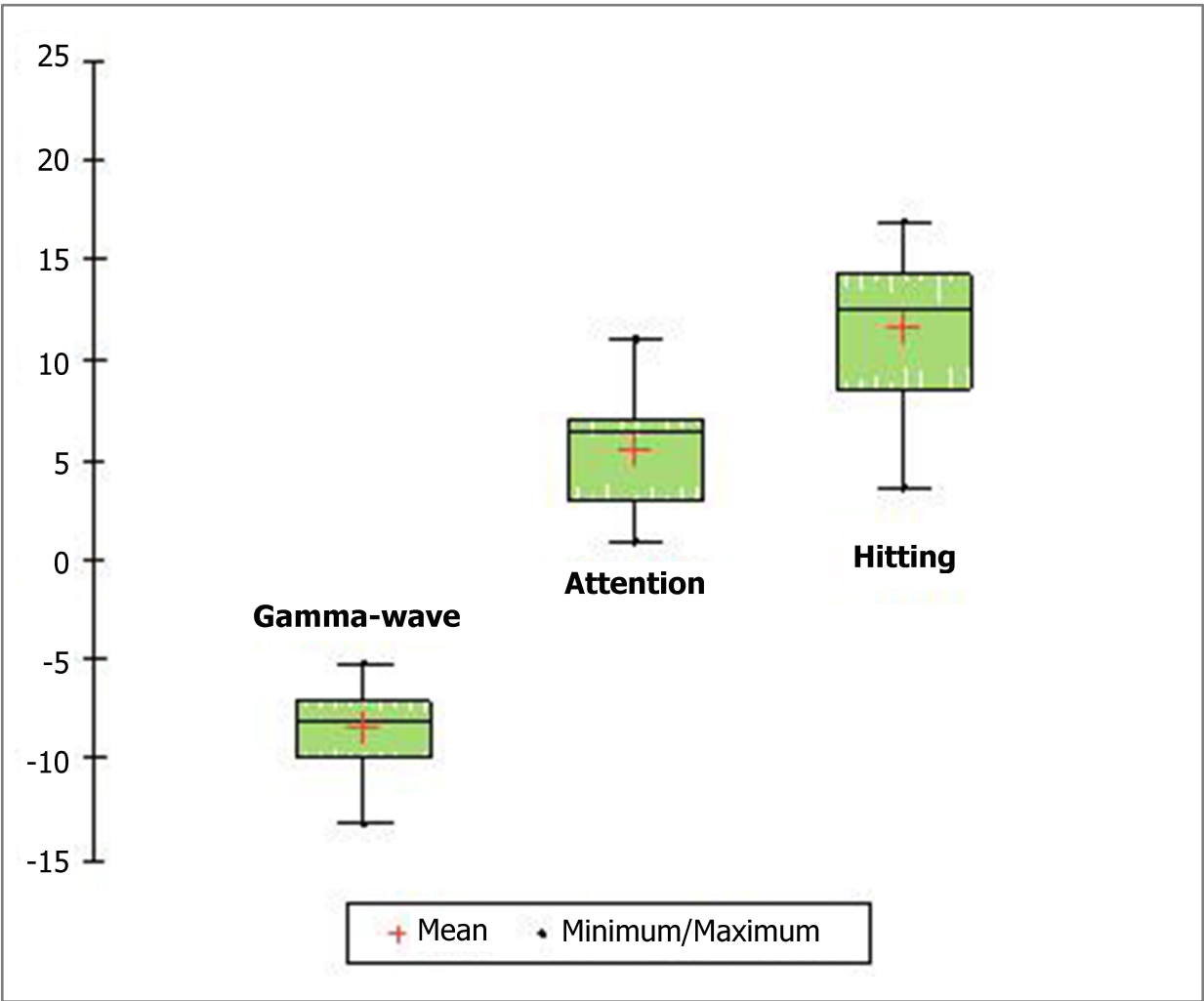

Figure 3. Gain score of gamma-wave, attention and hitting. Mean \pm SD: $(-8,26 \pm 2,00) ;(5,45 \pm 2,82) ;(11,67 \pm 3,39)$. 


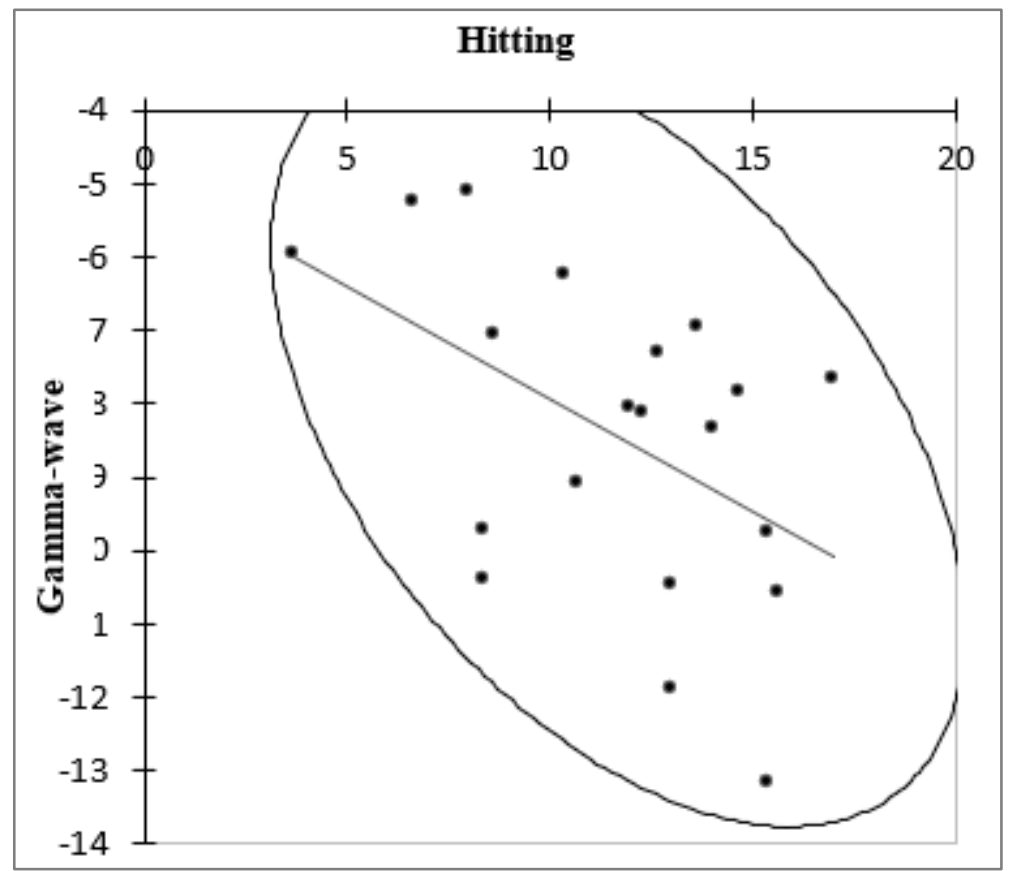

Figure 4. The scatter plot of significant pearson correlation between variables of gamma-wave with hitting performance. $\mathrm{R}=-0,495 ; \mathrm{p}-\mathrm{value}=0,026$.

This study also proved that there is a negative correlation between decrease gamma wave and increase hitting performance. That indicates the contribution of gamma-wave to hitting has $\mathrm{R}^{2}=0,245$ or $24,55 \%$. (So, it is possible that if the gamma wave is too high, it will interfere with the performance of the hitting skill, evidenced by the Pearson correlation test results at p-value 0.05. (See Fig. 4). In figure 5, proved of significant correlation between variables of gamma-wave with attention. The coefficients of determination $\mathrm{R}^{2}=0,207$ or $20,7 \%$ (contribution of gamma-wave to attention).

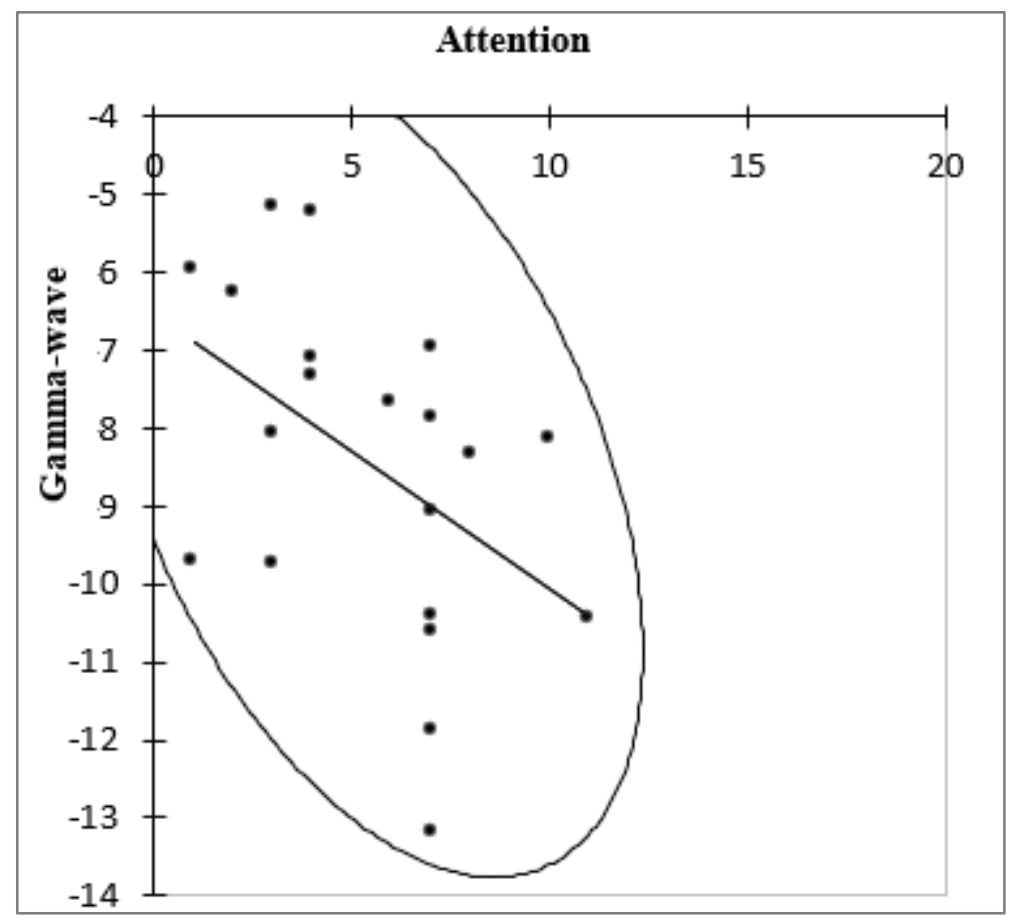

Figure 5. The Scatter plot of pearson correlation between variables of gamma wave with attention. $R=-0,455$; $p$-value $=0,044$. 


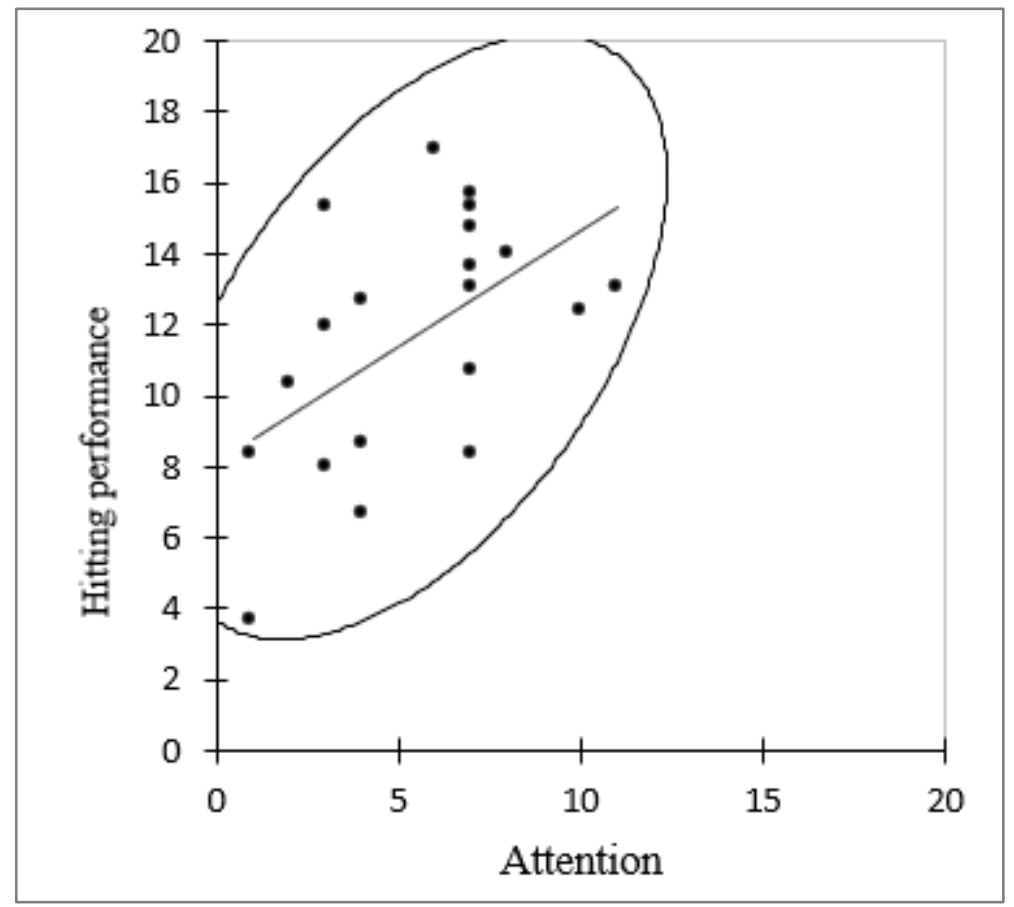

Figure 6. The Pearson correlation test was results of the correlation between attention and the performance of hitting skills resulted in a positive functional correlation $r=0.528$, a coefficient of determination of 0.279 , or a $27.9 \%$ contribution. The results of the statistical significance test resulted in a p-value of $0.0127 *$. This analysis means that attention ability will affect the improvement of hitting performance.

\section{Conclusions}

Electroencephalography (EEG) is an electrical activity in the brain, the amount of which depends on the situation and condition of a person[16] EEG will fluctuate depending on the psychological condition and cognitive abilities in dealing with and solving a problem[17], [18] The brain is an essential part of humans, which consists of neurons. These neurons will carry electrical signals from neurons to other neurons.[9], [19], [20] One of them is cognitive activity. Brain performance is influenced by mental conditions, lifestyle, and age.[21]

This study aims to determine and analyze the EEG signal biofeedback in the form of gamma waves that interact with physical activity in the form of softball hitting skills and attention. The activity of $\gamma$-wave reflects the association of selective attention between auditory and visual cortical areas.[22] If it looks at the results of the Pearson analysis test, all research variables' correlation has a significant correlation. According to this research, an effect was found from regular hitting training added by laying focus training and surprising results. The correlation between gamma wave and hitting skills found a negative correlation of -0.495 with a p-value of 0.026 . Decreasing gamma waves could affect performance by $24.5 \%$. If the gamma wave is too high, it will lose concentration and attention when hitting. The evidenced correlation between gamma wave variable and attention has a negative correlation of -0.455 with a p-value of 0.044; This also contributed to a $20.7 \%$ decrease in gamma on attention ability. Furthermore, this research conducted by Chu et al., found that a decrease in gamma waves during competition is identical to an increase in movement and a better response to a motion, on the other hand, an increase in gamma waves is identical to a decrease in movement and response to motion because an increase in gamma waves is associated with a decreased response. motion due to one's anxiety or hesitation in performing a movement, on the other hand, a decrease in gamma waves is associated with the emergence of better movements due to belief and less anxiety[22].

The result of another analysis test through Pearson correlation between attention and hitting skills has a positive functional correlation, with a value of $r=0.528$ with a coefficient of determination of 0.279 , this is evidence that attention can affect hitting performance by $27.9 \%$ with a statistical value of $p-0.0127$. Accordance with the prediction of the researchers that increased attention affects hitting ability. Same with Castaneda and Gray's research that the effect of attention is a crucial aspect because when someone is about to hit, the stimulus received is in the form of a ball which is then received by eye stimulation which is then transmitted to the brain to be immediately processed and responded to in the form of motion. because when it becomes a hitter, no one can help, with the interference from the audience and the high and varied speed of throwing the ball, which makes a hitter has to be able to focus his attention on the arrival of the ball, regardless of other disturbances[15]. The movement of hitting a softball ball is complex and unpredictable. refers to be a stimulus to increase anxiety[18], [23]-[27]. Excessive anxiety will affect the decrease in final 
attention and reduce performance in hitting a softball.

This present study on softball hitting provided a high correlation with gamma wave responses and attention. Regular, programmed, and continuous exercise and the application of specialized attention training will improve hitting performance. Future research plans will involve variable anxiety with a cortisol response biomarker.

\section{Acknowledgments}

This research will be dedicated to the progress and development of softball and baseball athletes in West Java province and the Indonesian elite athletes.

\section{REFERENCES}

[1] G. Cheron et al., "Brain oscillations in sport: Toward EEG biomarkers of performance," Front. Psychol., vol. 7, no. FEB, 2016.

[2] K. Hötting and B. Röder, "Beneficial effects of physical exercise on neuroplasticity and cognition," Neurosci. Biobehav. Rev., vol. 37, no. 9, pp. 2243-2257, 2013.

[3] C. Welfare and I. Gateway, "Understanding the Effects of Maltreatment on Brain Development How the brain develops Effects of maltreatment on brain development Implications for practice and policy How the Brain Develops," no. April, 2015.

[4] P. Engchuan, K. Wongsuphasawat, and P. Sittiprapaporn, "Brain electrical activity during bench press weight training exercise," Asian J. Med. Sci., vol. 10, no. 5, pp. 80-85, 2019.

[5] S. P. Bailey, E. E. Hall, S. E. Folger, and P. C. Miller, "Changes in EEG during graded exercise on a recumbent cycle ergometer," J. Sport. Sci. Med., vol. 7, no. 4, pp. 505$511,2008$.

[6] M. S. Lamba, "Impact of Teaching Time on Attention and Concentration," IOSR J. Nurs. Heal. Sci., vol. 3, no. 4, pp. 01-04, 2014.

[7] H. Ghasemzadeh and R. Jafari, "Coordination analysis of human movements with body sensor networks: A signal processing model to evaluate baseball swings," IEEE Sens. $J$. , vol. 11, no. 3, pp. 603-610, 2011.

[8] R. Robbins and M. Stonehill, "Investigating the NeuroSky MindWave ${ }^{\mathrm{TM}}$ EEG Headset," 2014.

[9] C. Amo, L. de Santiago, R. Barea, A. López-Dorado, and L. Boquete, "Analysis of gamma-band activity from human EEG using empirical mode decomposition," Sensors (Switzerland), vol. 17, no. 5, 2017.

[10] T. J. Hepler and D. L. Feltz, "Path analysis examining self-efficacy and decision-making performance on a simulated baseball task," Res. Q. Exerc. Sport, vol. 83, no. 1, pp. 55-64, 2012.

[11] R. Septian, J. D. K. N, and A. S. S, "Journal of Teaching Physical Education in Elementary School Increasing the Ability of Concentration Through the Implementation of Brain Gym research . Measuring instrument in this study using Concentration Grid,” vol. 2, no. 229, pp. 11-14, 2018.

[12] P. Mcgovern and K. Marr, "Softball Drills and Modified Games," in Softball Drills and Modified Games, the National and Academy Coaches Handbook.

[13] J. Sherwin, J. Muraskin, and P. Sajda, "You Can't Think and Hit at the Same Time: Neural Correlates of Baseball Pitch Classification," Front. Neurosci., vol. 6, no. December, pp. $1-11,2012$.

[14] J. C. Magalhães et al., "The influence of Levetiracetam in cognitive performance in healthy individuals: Neuropsychological, behavioral and electrophysiological approach," Clin. Psychopharmacol. Neurosci., vol. 13, no. 1, pp. 83-93, 2015.

[15] B. Castaneda and R. Gray, "Effects of focus of attention on baseball batting performance in players of differing skill levels," J. Sport Exerc. Psychol., vol. 29, no. 1, pp. 60-77, 2007.

[16] M. Bear, M; Connors, B; Paradiso, BOOK. NEUROSCIENCE Exploring the Brain, no. 1. 2014.

[17] S. Becker, "A computational principle for hippocampal learning and neurogenesis," Hippocampus, vol. 15, no. 6, pp. 722-738, Jan. 2005.

[18] S. D. Van Hove, "Prediction of softball batting success through attentional style by," 1984.

[19] B. J. Sadock and V. A. Sadock, Comprehensive Textbook \& Psichiatry, vol. 15, no. 7. Lippincott Williams \& Wilkins Publishers, 200AD.

[20] S. F. Cooke and T. V. P. Bliss, "Plasticity in the human central nervous system," Brain, vol. 129, no. 7, pp. 16591673, 2006.

[21] A. Azhari and F. I. Ammatulloh, "Classification of Concentration Levels in Adult-Early Phase using Brainwave Signals by Applying K-Nearest Neighbor," Signal Image Process. Lett., vol. 1, no. 1, pp. 14-24, 2019.

[22] D. Chu et al., "The correlation of brainwaves of Taekwondo athletes with training vis-à-vis competition performance-an explorative study," Int. J. Perform. Anal. Sport, vol. 18, no. 1, pp. 69-77, 2018.

[23] L. Kovářová and K. Kovář, "Concentration of attention as a predisposition of performance in junior categories in endurance sports," Acta Gymnica, vol. 40, no. 1, pp. 23-31, 2010.

[24] M. R. Rueda, M. I. Posner, and K. Mary, "Developmental Neuropsychology The Development of Executive Attention : Contributions to the Emergence of Self-Regulation," Dev. Neuropsychol., vol. 28, no. August, pp. 573-594, 2005.

[25] B. Olk, "Measuring the allocation of attention in the Stroop task: Evidence from eye movement patterns," Psychol. Res., vol. 77, no. 2, pp. 106-115, 2013.

[26] R. Booth and D. Sharma, "Stress reduces attention to irrelevant information: Evidence from the Stroop task," Motiv. Emot., vol. 33, no. 4, pp. 412-418, 2009.

[27] I. Bidzan-Bluma and M. Lipowska, "Physical activity and cognitive functioning of children: A systematic review," Int. J. Environ. Res. Public Health, vol. 15, no. 4, 2018. 